\begin{tabular}{|c|l|}
\hline Title & Magnetic Interactions of ( $\mu$-Pyrazolato)-Bridged Copper(II) Complexes Determined by Solid-State MA S NMR \\
\hline Author(s) & Oomomo, Takayuki; Maruta, Goro; Takeda, Sadamu \\
\hline Citation & $\begin{array}{l}\text { Polyhedron, 24(16-17), 2431-2436 } \\
\text { https://doi.org/10.1016/.poly.2005.03.049 }\end{array}$ \\
\hline Issue Date & 2005-11-17 \\
\hline Doc URL & http://hdl.handle.net/2115/8297 \\
\hline Type & article (author version) \\
\hline Note(URL) & http://www.sciencedirect.com//science/ournal 02775387 \\
\hline File Information & T060oomomo2.pdf \\
\hline
\end{tabular}

Instructions for use 


\title{
Magnetic Interactions of ( $\mu$-Pyrazolato)-Bridged Copper(II) Complexes Determined by Solid-State MAS NMR
}

\author{
Takayuki Oomomo Goro Maruta* Sadamu Takeda \\ Division of chemistry, Graduate School of Science, Hokkaido University, Sapporo, \\ 060-0810, Japan
}

\begin{abstract}
We investigated electron spin densities of pyrazolato-bridged complexes $\left[\mathrm{Cu}(\mathrm{pz})_{2}\right]_{n} \mathbf{1}$ and $\left[\mathrm{Cu}_{2}(\mathrm{pz})_{2}\left(\mathrm{NO}_{3}\right)\left(\mathrm{H}_{2} \mathrm{O}\right)(\text { phen })_{2}\right] \mathrm{NO}_{3} \mathbf{2}(\mathrm{Hpz}=$ pyrazole, phen = 1, 10-phenanthroline $)$ using solid-state high-resolution NMR to elucidate the magnetic interaction paths with the help of molecular orbital theory. We prepared deuterated analogue of these complexes, $\mathbf{1}-\mathrm{d}_{6}$ and $\mathbf{2}-\mathrm{d}_{6}$, to measure temperature dependence of ${ }^{2} \mathrm{H}-$ and ${ }^{13} \mathrm{C}-\mathrm{NMR}$ shifts between $190 \mathrm{~K}$ and $350 \mathrm{~K}$. The hyperfine coupling constants (HFCCs) and electron spin densities were determined from the slopes of the shifts as a function of the magnetic susceptibilities. The derived spin densities were all positive, which indicates the dominant magnetic interaction paths of these complexes are not $\pi$ but $\sigma$ orbitals of the pyrazolate ligand. The NMR results reasonably agreed with those of density functional theory (DFT) calculations for molecular models of $\mathbf{1}$ and $\mathbf{2}$.
\end{abstract}

Key words: local magnetic structures, solid-state ${ }^{13} \mathrm{C}-\mathrm{NMR}$, solid-state ${ }^{2} \mathrm{H}-\mathrm{NMR}$, hyperfine coupling constant, distribution of electron spin density

\section{Introduction}

Solid-state NMR has been widely used to study the magnetic properties of coordination compounds [1-4]. In particular, magic angle spinning (MAS) NMR spectroscopy is a powerful technique for obtaining high-resolution NMR spectra of paramagnetic metal complexes [4-8]. In the beginning of 1990's, it was demonstrated that ${ }^{13} \mathrm{C}-,{ }^{1} \mathrm{H}$-, and ${ }^{2} \mathrm{H}$ MAS NMR spectra of deuterated paramagnetic solids exhibit well-resolved lines without ${ }^{1} \mathrm{H}$ decoupling. $[9,10]$ Since

\footnotetext{
* Corresponding author. Tel.: +81 11-706-3504; Fax:+81 11-706-4841.

Email address: maruta@sci.hokudai.ac.jp (Goro Maruta).
} 
then, deuterated compounds have been used in a variety of NMR studies: transition metal complex [5], model compounds [6] or mutant [11] of metalloproteins, organic ferromagnets [12,13], metallocenes [14], cathode materials [15], two-dimensional [16] and REDOR [17] experiments. Nevertheless, its applications to polynuclear complexes, especially to coordination polymers, are still rare.

A large number of Polynuclear copper(II) complexes have been synthesized and structurally characterized so far, and a number of magneto-structural correlations are proposed. For example, there exists linear correlation between the magnetic-exchange coupling constant $-2 J$ and the $\mathrm{Cu}-\mathrm{O}-\mathrm{Cu}$ angles in bis $(\mu-$ hydroxo)-bridged binuclear copper(II) complexes [18]. While this correlation is well explained by molecular-orbital theory [19], it is usually difficult to elucidate the nature of magnetic interactions in complexes bridged by heterocyclic ligands, such as pyridazine [20], imidazolate [21], and pyrazolate [22]. One of this reasons is that these heterocyclic ligands seldom bridge the metal atoms without additional bridging ligands (hydroxo and chloro, for example) or functional groups to chelate the metal ion. These chemical modifications obscure the inherent contribution from the bridging ligand to the magnetic interaction. As far as we know, there are seven structurally-characterized polynuclear copper(II) complexes which are bridged by two unsubstituted pyrazolate anions, $\left(\mathrm{C}_{3} \mathrm{H}_{3} \mathrm{~N}_{2}^{-}\right.$, Fig. 1(a)) [23-27]. These are antiferromagnetically-coupled coordination polymer [23] and binuclear complexes [24-27] with $-2 J$ values of $143-270 \mathrm{~cm}^{-1}$. The superexchange pathway has been proposed to be the $\pi$ system of the pyrazolates for the polymeric complex [23], while the $\sigma$ system has been proposed for the others on the basis of extended Hückel MO calculations.

In this paper, we investigate poly- and bi-nuclear copper(II) complexes $\left[\mathrm{Cu}(\mathrm{pz})_{2}\right]_{n}$ 1 and $\left[\mathrm{Cu}_{2}(\mathrm{pz})_{2}\left(\mathrm{NO}_{3}\right)\left(\mathrm{H}_{2} \mathrm{O}\right)(\text { phen })_{2}\right] \mathrm{NO}_{3} 2(\mathrm{Hpz}=$ pyrazole, phen $=1,10-$ phenanthroline) which have simple pyrazolate ligands as bridges. In $\mathbf{1}$, coordination geometry around the copper atom is a distorted tetrahedron having exact $D_{2}$ symmetry and in $\mathbf{2}$ is the geometry between trigonal bipyramidal and square pyramidal. These complexes have electron spin of $S=1 / 2$ at copper(II) ion. It has been reported that the $-2 J$ value of $\mathbf{1}$ and $\mathbf{2}$ is $162,143 \mathrm{~cm}^{-1}$, respectively, indicating the existence of an antiferromagnetic interaction. Delocalized or polarized electron spin of the bridging pyrazolate is believed to mediate antiferromagnetic exchange interaction [23,27]. There is continuing interest in molecular orbitals that determine the local magnetic structures of paramagnetic complexes. We measured solid-state high-resolution NMR spectra of deuterated analogues of the complexes to elucidate which molecular orbital works as superexchange pathway. 


\section{Experimental}

\subsection{Sample Preparation}

Perdeuterated pyrazole was prepared by catalytic exchange reaction [28]. Deuterated analogues of $\mathbf{1}$ and $\mathbf{2}$ were prepared in a similar manner to the literature methods $[23,27]$ using the perdeuterated pyrazole. The samples $\mathbf{1}-\mathrm{d}_{6}$ and $\mathbf{2}-\mathrm{d}_{6}$ were identified with elemental analysis and powder X-ray diffraction.

\subsection{Solid-state high-resolution NMR}

${ }^{2} \mathrm{H}$ MAS NMR and the ${ }^{13} \mathrm{C}$ MAS NMR spectra of $\mathbf{1}-\mathrm{d}_{6}$ and $\mathbf{2}-\mathrm{d}_{6}$ were measured by a modified TOSS pulse sequence $[29,30]$ for powder crystalline samples at an external magnetic field of $7.05 \mathrm{~T}$ with a Bruker DSX300 spectrometer. A simple $\pi$-echo pulse sequence was also employed to measure the spinning sideband patterns. The spinning speeds of the samples were $7 \mathrm{kHz}$ and $9 \mathrm{kHz}$ for $1-\mathrm{d}_{6}$ and $2-\mathrm{d}_{6}$, respectively. The ${ }^{2} \mathrm{H}$ - and ${ }^{13} \mathrm{C}-\mathrm{NMR}$ spectra were measured from 190 to $350 \mathrm{~K}$. The thermometer of the MAS NMR probe and an effect of the spinning speed on temperature-increase were carefully calibrated using $\mathrm{Pb}\left(\mathrm{NO}_{3}\right)_{2}$. The uncertainty of the temperature measurement after the calibration was $4 \mathrm{~K}$, and the temperature fluctuation during the accumulation was within $1 \mathrm{~K}$ [12]. The NMR shifts were measured from TMS using methanol- $\mathrm{d}_{4}$ $\left({ }^{2} \mathrm{H}\right)$ and hexamethylbenzene $\left({ }^{13} \mathrm{C}\right)$ as the second reference.

\subsection{Electronic structure calculations}

Density functional theory (DFT) calculations were performed at the level of UB3LYP/LanL2DZ using Gaussian98 program package [31]. We used $\left[\mathrm{Cu}_{2}\left(\mathrm{pz}_{2} \mathrm{Cl}_{4}\right]^{2-}\right.$ as a molecular model of $\mathbf{1}$ because DFT calculations of one-dimensional polymeric complex is difficult. In the model molecule, copper atoms are bridged by two pyrazolate ligands and each copper ion is coordinated by two chlorine atoms. As a model of $\mathbf{2},\left[\mathrm{Cu}_{2}(\mathrm{pz})_{2}(\mathrm{NO} 3)\left(\mathrm{H}_{2} \mathrm{O}\right)(\mathrm{phen})_{2}\right]^{+}$itself was used. The geometrical parameters were taken from their crystal structures. 


\section{Results and discussion}

\subsection{Spin densities of polynuclear copper(II) complex $\left[\mathrm{Cu}(\mathrm{pz})_{2}\right]_{n}$}

Figure 1(a) and 1(b) show ${ }^{2} \mathrm{H}$ and ${ }^{13} \mathrm{C}$ MAS NMR spectra of $1-\mathrm{d}_{6}$ at $276 \mathrm{~K}$, respectively. Two peaks were observed both in ${ }^{2} \mathrm{H}$ NMR spectrum (A and B in Fig. 1(a)) and in ${ }^{13} \mathrm{C}$ NMR spectrum (C and D in Fig. 1(b)). These peaks were assigned to nuclei of the pyrazolate ligand as shown in Fig. 1. This assignment was based on the relative intensity of the NMR signals including spinning sidebands (data not shown). High frequency shifts were observed for the four NMR signals, indicating positive HFCCs of these nuclei. Since paramagnetic shift $\delta_{\text {para }}$ is proportional to the magnetic susceptibility $\chi$,

$$
\delta_{\text {iso }}=\delta_{\text {para }}+\delta_{\text {dia }}=\frac{A_{\mathrm{N}} \cdot \chi}{N_{\mathrm{A}}\left(\gamma_{\mathrm{N}} / 2 \pi\right) g \beta}+\delta_{\mathrm{dia}}
$$

the HFCC $\left(A_{\mathrm{N}}\right.$ in hertz) can be determined from the temperature dependence of the isotropic shift $\delta_{\text {iso }}$ with the help of the magnetic susceptibility. In Eq. $1, N_{\mathrm{A}}$ is the Avogadro constant, $\gamma_{\mathrm{N}}$ is gyromagnetic ratio of the nucleus, $g$ is the isotropic $g$ value of the complex, $\beta$ is the Bohr magneton, and $\delta_{\text {dia }}$ is the temperature-independent chemical shift [32]. Temperature dependences of ${ }^{2} \mathrm{H}$ and ${ }^{13} \mathrm{C}$ NMR spectra of $1-\mathrm{d}_{6}$ are summarized in Fig. 2(a) and 2(b). The NMR signals were shifted to higher frequencies with decreasing temperature. Magnetic susceptibility of $\mathbf{1}$ was interpreted in terms of one-dimensional antiferromagnetic Heisenberg model [33]:

$$
\chi=\frac{N_{\mathrm{A}} g^{2} \beta^{2}}{k T} \cdot \frac{0.250+0.14995 x^{-1}+0.30094 x^{-2}}{1+1.986 x^{-1}+0.68854 x^{-2}+6.0626 x^{-3}}
$$

where $x=k T /|J|$. The magnetic-exchange coupling constant, $-2 J$ and the $g$ value of 1 are reported as $162 \mathrm{~cm}^{-1}$ and 2.13, respectively [23]. Because the paramagnetic shift is proportional to the magnetic susceptibility, the observed ${ }^{2} \mathrm{H}-\mathrm{NMR}$ isotropic shifts of $\mathbf{1}-\mathrm{d}_{6}$ were plotted as a function of the magnetic susceptibility of $\mathbf{1}$ (Figure 3). From the slope of the line, we determined the HFCCs of deuteron in the use of Eq. 1 as listed in Table 1. The HFCCs of carbon were also deduced in the same manner. Here we mention the observed HFCCs $\left(A_{\mathrm{N}}\right)$ is composed of the Fermi contact $\left(A_{\mathrm{Fermi}}\right)$ and the pseudo contact $\left(A_{\text {pseudo }}\right)$ terms [32]

$$
\begin{gathered}
A_{\mathrm{N}}=A_{\text {Fermi }}+A_{\text {pseudo }} \\
A_{\text {pseudo }}=\frac{1}{3} \frac{\gamma_{\mathrm{N}}}{2 \pi} g \beta\left(\frac{g_{\|}^{2}}{g^{2}}-\frac{g_{\perp}^{2}}{g^{2}}\right) \frac{1}{r^{3}}\left(3 \cos ^{2} \theta-1\right)
\end{gathered}
$$



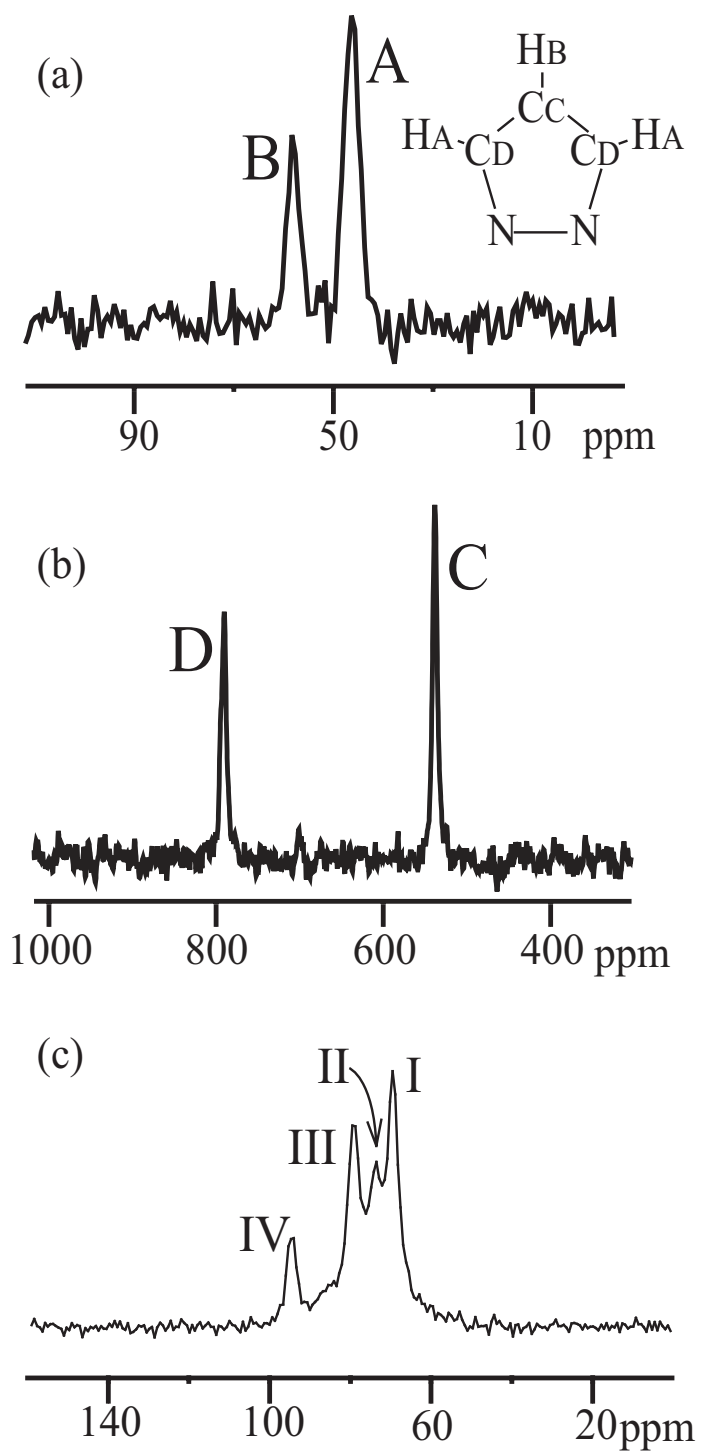

(d)

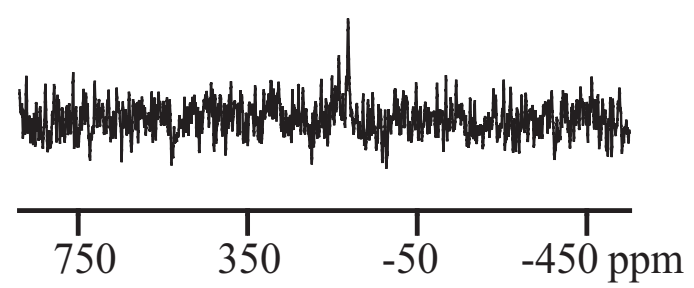

Fig. 1. Solid-state high-resolution NMR spectra of deuterated complexes $1-\mathrm{d}_{6}$ and 2- $\mathrm{d}_{6}$ : (a) ${ }^{2} \mathrm{H}-\mathrm{NMR}$ spectrum of $\mathbf{1}-\mathrm{d}_{6}$ at $276 \mathrm{~K}$, (b) ${ }^{13} \mathrm{C}-\mathrm{NMR}$ spectrum of $\mathbf{1}-\mathrm{d}_{6}$ at $276 \mathrm{~K}$, (c) ${ }^{2} \mathrm{H}-\mathrm{NMR}$ spectrum of $\mathbf{2}-\mathrm{d}_{6}$ at $190 \mathrm{~K}$, (d) ${ }^{13} \mathrm{C}-\mathrm{NMR}$ spectrum of $\mathbf{2}-\mathrm{d}_{6}$ at $300 \mathrm{~K}$. Additionally, alphabetical scheme for the hydrogen and carbon atoms of pyrazolate ligand is described for Fig. 1(a) and 1(b). 
(a)

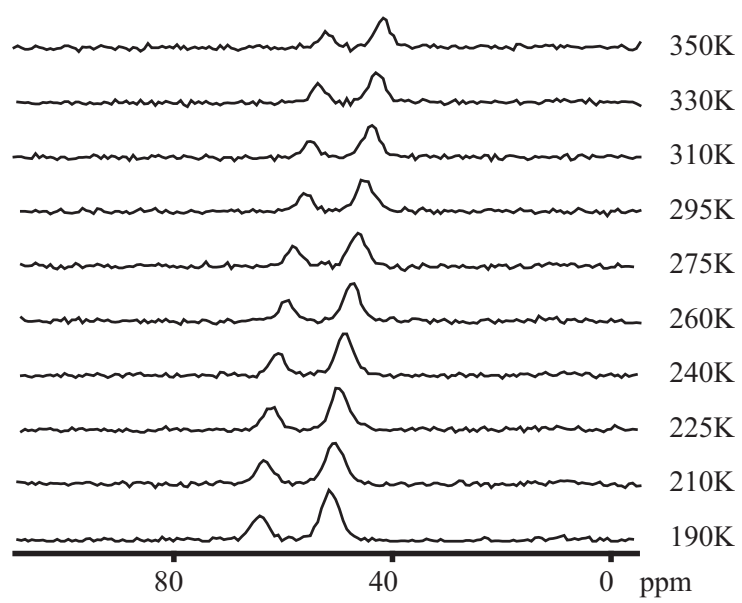

(b)

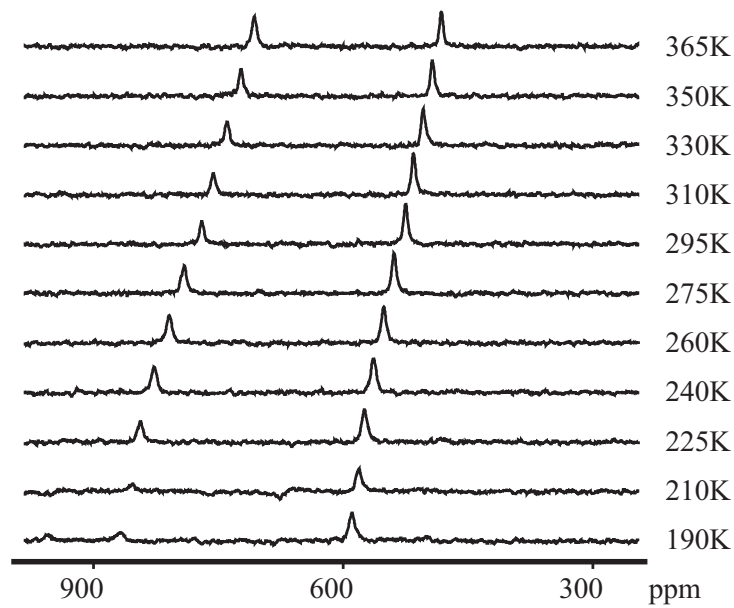

(c)

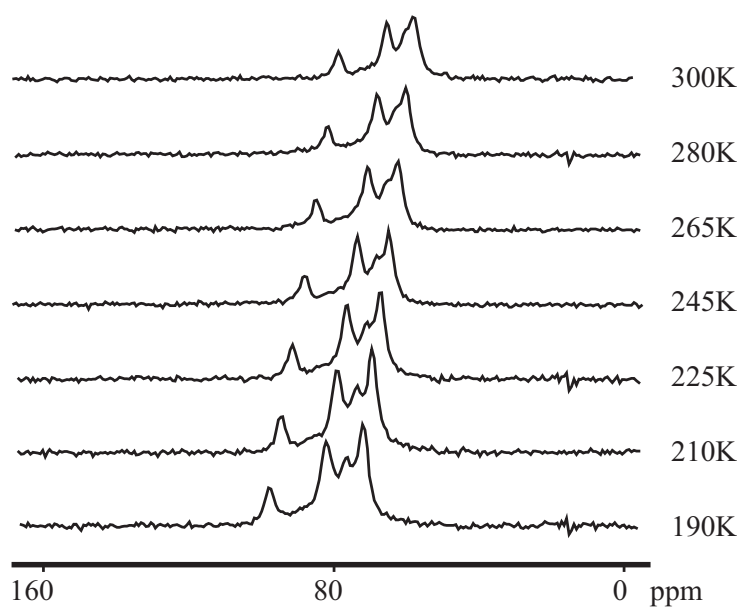

Fig. 2. Temperature dependence of the MAS NMR spectra: $(\mathrm{a})^{2} \mathrm{H}-\mathrm{NMR}$ spectra of 1- $\mathrm{d}_{6},(\mathrm{~b})^{13} \mathrm{C}-\mathrm{NMR}$ spectra of $\mathbf{1}-\mathrm{d}_{6},(\mathrm{c})^{2} \mathrm{H}-\mathrm{NMR}$ spectra of $\mathbf{2}-\mathrm{d}_{6}$. 


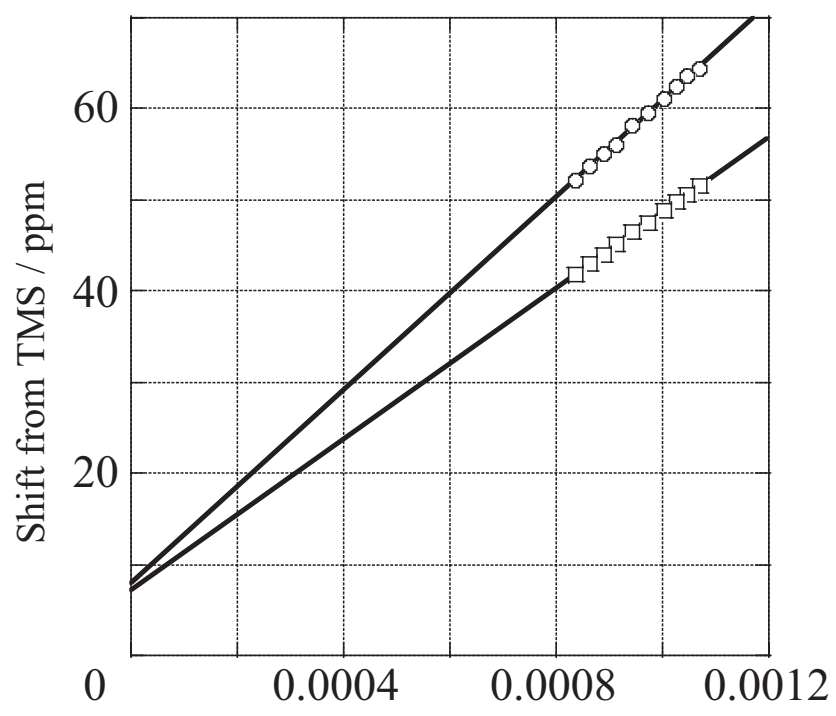

Magnetic susceptibility $/ \mathrm{cm}^{3} \mathrm{~mol}^{-1}$

Fig. 3. A plot of the isotropic shifts as a function of magnetic susceptibility in ${ }^{2} \mathrm{H}-\mathrm{NMR}$ spectra of $1-\mathrm{d}_{6}: \bigcirc$, the shifts derived from peak $\mathrm{B}$; $\square$, the shifts derived from peak A.

where $r$ is the length of a vector $r$ from the copper ion to the nucleus, $\theta$ is the polar angles of the vector with respect to the principal axis of $g$-tensor. However, values of the $A_{\text {pseudo }}$ were estimated to be less than 0.05 and 0.1 $\mathrm{MHz}$ for ${ }^{2} \mathrm{H}$ and ${ }^{13} \mathrm{C}$ NMR shifts of $1-\mathrm{d}_{6}$, respectively, which shows the contribution of $A_{\text {pseudo }}$ to the observed $A_{\mathrm{N}}$ is vanishingly low. Thus we can regard the observed HFCCs as Fermi contact term $A_{\mathrm{Fermi}}$. Then the s-electron spin densities for $\mathrm{H}$ and $\mathrm{C}$ atoms of $1-\mathrm{d}_{6}$ were determined from $A_{\mathrm{N}}$ as

$$
A_{\mathrm{Fermi}}=\rho^{\mathrm{s}} A_{f}
$$

where $\rho^{\mathrm{s}}$ is the s-electron spin density of the atom and $A_{f}$ is the value of the HFCC when the s orbital is singly occupied $\left(\rho^{\mathrm{s}}=1\right)$. The experimental s-electron spin densities and computed atomic spin densities $\rho^{\text {atom }}$ are also listed in Table 1.

\subsection{Magnetic interaction path of polynuclear copper(II) complex $\left[\mathrm{Cu}(\mathrm{pz})_{2}\right]_{n}$}

We found that the s-electron spin densities of carbon and hydrogen atoms in pyrazolate are all positive values. Here we discuss the magnetic interaction path of $\mathbf{1}$ on the basis of the NMR results with the help of molecular orbitals. There are two candidates for the interaction pathway in terms of molecular orbital theory: $\pi$-electron system and $\sigma$-electron system in the pyrazolate anion. The $\pi$-electron system of the anion is a 6 -electron 5 -orbital system including HOMO and LUMO of an imaginary isolated pyrazolate ligand. The 
HFCCs and electron spin densities in $\mathbf{1}-\mathrm{d}_{6}$ and $\mathbf{2}-\mathrm{d}_{6}$.

\begin{tabular}{|c|c|c|c|c|}
\hline & \multicolumn{2}{|c|}{ NMR experiment } & \multicolumn{2}{|c|}{ DFT calculation } \\
\hline & $\mathrm{HFCC} / \mathrm{MHz}$ & s-electron spin density & $\mathrm{HFCC} / \mathrm{MHz}$ & atomic spin density \\
\hline \multicolumn{5}{|l|}{$1-d_{6}$} \\
\hline $\mathrm{A}$ & +0.31 & +0.001 & +0.29 & +0.001 \\
\hline B & +0.39 & +0.002 & +0.24 & +0.000 \\
\hline $\mathrm{C}$ & +7.81 & +0.003 & +5.58 & +0.006 \\
\hline $\mathrm{D}$ & +5.30 & +0.002 & +9.79 & -0.001 \\
\hline \multicolumn{5}{|l|}{$2-\mathrm{d}_{6}$} \\
\hline I & +0.32 & +0.001 & & \\
\hline II & +0.37 & +0.002 & & \\
\hline III & +0.38 & +0.002 & & \\
\hline IV & +0.44 & +0.002 & & \\
\hline $\mathrm{H} 1$ & & & +0.28 & +0.001 \\
\hline $\mathrm{H} 2$ & & & +0.37 & +0.001 \\
\hline H3 & & & +0.45 & +0.001 \\
\hline $\mathrm{H} 4$ & & & +0.45 & +0.001 \\
\hline $\mathrm{H} 5$ & & & +0.40 & +0.001 \\
\hline $\mathrm{H} 6$ & & & +0.42 & +0.001 \\
\hline
\end{tabular}

$\sigma$-electron system of the anion is a 4-electron 2-orbital system mainly composed of two lone electron-pair of the two nitrogen atoms. We obtained these orbitals by extended Hückel MO calculations on an isolated pyrazolate anion and the qualitative character of these systems was not changed by higher level of calculation. When the pyrazolate coordinates to paramagnetic metal ions, electron spin densities is induced by delocalization and/or polarization mechanisms and the spin density distribution of the ligand depends on which mechanism is dominant. In the $\pi$-system, the s-electron spin densities of $\mathrm{H}$ and $\mathrm{C}$ atoms in pyrazolate ligand are zero at the first approximation because they are on the node of the $\pi$-orbitals. However, the s-electron spin density can be finite on the constituent atoms due to spin polarization mechanism [34]. Spin polarization is that on any $\mathrm{CH} \sigma$-bond unpaired electron in $2 \mathrm{p} \pi$-orbital attracts the electron of the same spin of $\mathrm{CH} \sigma$-bonding electron pair. As a result, the sign of s-electron spin density of a carbon atom is equal to that of $\pi$-electron spin density, and the adjacent hydrogen atom has the opposite sign to the unpaired $\pi$-electron. Therefore, $\mathrm{CH} \sigma$-bonding spin on the $\mathrm{H}$ site is consequently opposite in sign to the s-electron spin on the $\mathrm{C}$ site if the $\pi$ - 
spin polarization is dominant. On the other hand, in the $\sigma$-system, s-orbitals of $\mathrm{H}$ and $\mathrm{C}$ atoms have non-zero $\mathrm{MO}$ coefficients of the non-bonding orbitals which are mainly localized on $\mathrm{N}$ atoms. Thus the signs of the s-electron spin densities on the $\mathrm{H}$ and $\mathrm{C}$ sites become all positive when the $\mathrm{N}$ atoms have positive spin densities. In experimental NMR data, the signs of s-electron spin densities on the $\mathrm{H}$ and $\mathrm{C}$ sites of pyrazolate ligand were all positive. Therefore the magnetic interaction path of 1 cannot be the $\pi$-system on the assumption that the magnetic interaction path should dominate the local magnetic structure of the ligand. Consequently, the path of $\mathbf{1}$ is the $\sigma$-system in view of the property of the $\sigma$-orbitals. We obtained the HFCCs $\left(A_{\mathrm{Fermi}}\right)$ and atomic electron spin densities $\rho^{\text {atom }}$ of $\mathbf{1}$ using the DFT calculations. The calculated values of $A_{\text {Fermi }}$ were $0.29,0.24,5.58$ and $9.79 \mathrm{MHz}$ for the peak $\mathrm{A}, \mathrm{B}, \mathrm{C}$ and $\mathrm{D}$, respectively, and atomic spin densities were positive except for peak D. This small negative value of $\rho^{\text {atom }}$ indicates that $\pi$-spin polarization occurs slightly with the dominant $\sigma$-delocalization mechanism. We concluded that the dominant magnetic interaction path in $\mathbf{1}$ is the $\sigma$-electron system of the pyrazole ligand.

3.3 Spin densities and magnetic interaction path of binuclear copper(II) complex $\left[\mathrm{Cu}_{2}(\mathrm{pz})_{2}\left(\mathrm{NO}_{3}\right)\left(\mathrm{H}_{2} \mathrm{O}\right)(\text { phen })_{2}\right] \mathrm{NO}_{3}$

Figure 1(c) and 1(d) illustrate ${ }^{2} \mathrm{H}$ and ${ }^{13} \mathrm{C}$ MAS NMR spectra of $2-\mathrm{d}_{6}$ at 190 $\mathrm{K}$ and $300 \mathrm{~K}$, respectively. As shown in Fig. 1(d), we could not observe a ${ }^{13} \mathrm{C}$ NMR signal of $2-\mathrm{d}_{6}$ under our experimental condition. A peak around 150 ppm is probably due to impurity or background. The reason is ascribable to longer electron spin relaxation time $T_{1 \mathrm{e}}$ of $\mathbf{2}-\mathrm{d}_{6}$ or heteronuclear dipole-dipole interactions between protons in 1,10-phenanthroline ligand and carbon nuclei. We observed four ${ }^{2} \mathrm{H}$ NMR signals of I, II, III and IV as shown in Fig. 1(c). Because $\left[\mathrm{Cu}_{2}(\mathrm{pz})_{2}\left(\mathrm{NO}_{3}\right)\left(\mathrm{H}_{2} \mathrm{O}\right)(\text { phen })_{2}\right]^{+}$has no symmetry element, complex 2- $\mathrm{d}_{6}$ has six nonequivalent deuterium atoms in the two pyrazolate ligands. One-to-one assignment of the four peaks to the six hydrogen of the pyrazolate ligands could not be achieved. It is, however, obvious that all of the four signals have positive HFCCs from their high frequency shifts as is observed for 1- $\mathrm{d}_{6}$. The temperature dependence of ${ }^{2} \mathrm{H}$ MAS NMR spectrum is shown in Fig. 2(c). All of the four peaks were shifted to higher frequencies with decreasing temperature. Magnetic susceptibility of $\mathbf{2}$ was interpreted with singlet-triplet model [27]

$$
\chi=\left(\frac{N_{\mathrm{A}} g^{2} \beta^{2}}{k T}\right)\left[3+\exp \left(\frac{-2 J}{k T}\right)\right]^{-1}
$$

where $-2 J$ and $g$ value of 2 are reported as $143 \mathrm{~cm}^{-1}$ and 2.14, respectively [27]. The four paramagnetic shifts in the ${ }^{2} \mathrm{H}$ MAS NMR spectrum of $2-\mathrm{d}_{6}$ 


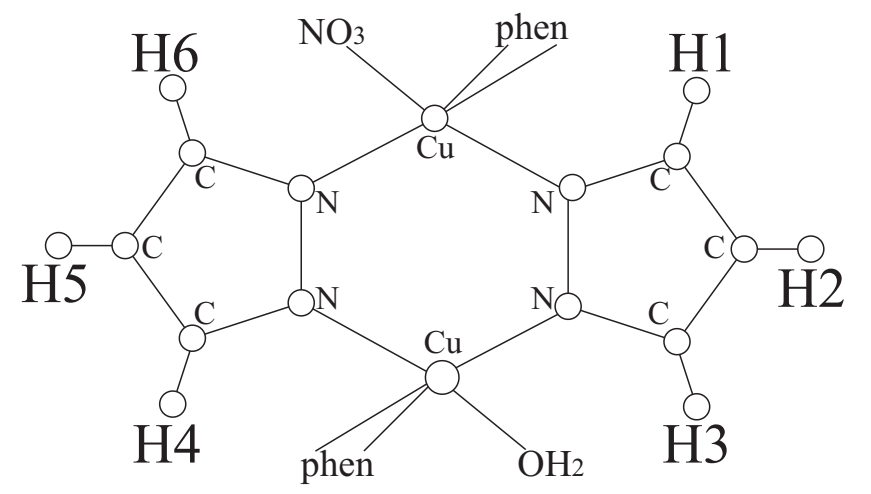

Fig. 4. Numbering scheme for the hydrogen atoms of $\mathbf{2}$.

were plotted as a function of the magnetic susceptibility, then the HFCCs and electron spin densities in $\mathbf{2}-\mathrm{d}_{6}$ were obtained in a similar manner to $\mathbf{1}-\mathrm{d}_{6}$. The HFCCs and the spin densities are listed in Table 1 . As were obtained for $\mathbf{1}$, the pseudo contact term was evaluated for 2 using Eq. 4 . Values of the $A_{\text {pseudo }}$ are estimated to be less than $0.05 \mathrm{MHz}$ for ${ }^{2} \mathrm{H}$ shifts. As compared to the HFCCs on Table 1, contribution of the $A_{\text {pseudo }}$ to the obtained HFCCs is vanishingly low again. Therefore the experimental HFCCs in $2-\mathrm{d}_{6}$ can be also thought of as Fermi contact term. The HFCCs and atomic spin densities from the DFT calculations in $\mathbf{2}$ were obtained as shown in Table 1, and the numbering scheme for the hydrogen atoms is shown in Fig. 4. Here we compared the result of the calculations with the experimental values in $2-\mathrm{d}_{6}$ to assign I, II, III and IV to hydrogen atoms of the pyrazolate ligands. The one-to-one assignment could not be also achieved. However, the experimental HFCC fell within 0.32-0.44 $\mathrm{MHz}$ and the calculated HFCC fell within 0.28-0.45 MHz. We concluded that the HFCCs of the pyrazolate ligands are similar positive values to each other.

Electron spin densities on $\mathrm{H}$ sites in $\mathbf{2}-\mathrm{d}_{6}$ as well as in $\mathbf{1}-\mathrm{d}_{6}$ were all positive values. As discussed in the magnetic interaction of $\mathbf{1}$, either $\sigma$ or $\pi$ orbital of pyrazolate ligand is the magnetic interaction path in the binuclear complex 2 . If $\pi$-orbitals are used, signs of the spin densities on $\mathrm{H}$ sites in $2-\mathrm{d}_{6}$ would not be all the same. The signs deduced from the experiment on $\mathbf{2}-\mathrm{d}_{6}$ correspond with properties of the $\sigma$-system. The magnetic interaction path of $\mathbf{2}-\mathrm{d}_{6}$ is also $\sigma$-orbitals of pyrazolate ligands.

It should be noted that the HFCCs of $\mathbf{1}-\mathrm{d}_{6}$ and $\mathbf{2}-\mathrm{d}_{6}$ are almost the same values, which indicates that the spin density distribution are almost the same at the pyrazolate ligands in the both compounds. Moreover, the $-2 J$ values of the these compounds are approximately the same though they are very different in coordination geometry. Plass et al. [21] reported that their mono-imidazolatebridged binuclear copper(II) complexes $\left[\mathrm{Cu}_{2}(\mathrm{dien})_{2}(\mathrm{~L})\right]\left(\mathrm{ClO}_{4}\right)_{3}$ (L:imizolate or substituted imidazolates) have no simple magneto-structural correlation and concluded that the magnetic interactions between the copper(II) ions is dom- 
inated by the $\sigma$ exchange pathway through the bridging imidazolate ligand. However, it should be stressed that there is a magneto-structural correlation in bis-pyrazolate-bridged copper(II) complex [27]. Matsushima et al. found that square-planar and square-pyramidal complexes, which have the well-defined $\mathrm{d}_{x^{2}-y^{2}}$ orbital as the magnetic orbital, have larger $-2 J$ values than trigonal bipyramidal complexes. The magnetic orbitals of the latter compounds are so distorted from the $\mathrm{d}_{x^{2}-y^{2}}$ orbital that the orbital-overlap integrals between copper (II) centers and pyrazolate ligands decrease. The distorted tetrahedral geometry around the copper atom in $\mathbf{1}$ also deviate the magnetic orbital from the ideal $\mathrm{d}_{x^{2}-y^{2}}$ orbital. This is the reason why antiferromagnetic interaction in $\mathbf{1}$ is as weak as in $\mathbf{2}$.

\section{Conclusion}

We investigated magnetic interaction paths for complex $\mathbf{1}$ and $\mathbf{2}$, which include heterocyclic ligand, by means of solid-state MAS NMR measurement. We found the electron spin of $S=1 / 2$ of $\mathrm{Cu}(\mathrm{II})$ ion in $\mathbf{1}$ and $\mathbf{2}$ delocalize over the pyrazolate ligand via $\sigma$-orbitals. The experimental values of HFCCs agreed with those calculated on the basis of DFT. It is important that the observed s-electron spin densities are all positive values in $\mathbf{1}-\mathrm{d}_{6}$ and $\mathbf{2}-\mathrm{d}_{6}$. Taking molecular orbitals of pyrazolate ligand into account, the NMR result cannot be explained by $\pi$-spin polarization. We concluded that the magnetic interaction paths of $\mathbf{1}$ and $\mathbf{2}$ are not $\pi$ but $\sigma$-electron system of the pyrazolate..

\section{Acknowledgements}

This research was supported by Grant-in-Aid for Young Scientists (No. 14740371) and for Scientific Research on Priority Areas "Application of Molecular Spins" (No. 15087201) from the Ministry of Education, Culture, Sports, Science and Technology of Japan.

\section{References}

[1] A. Lascialfari, Z. H. Jang, F. Borsa, P. Carretta, D. Gatteschi, Phys. Rev. Lett. 81 (1998) 3773.

[2] R. M. Achey, P. L. Kuhns, A. P. Reyes, W. G. Moulton, N. S. Dalal, Phys. Rev. B64 (2001) 064420. 
[3] S. Takaishi, Y. Tobu, H. Kitagawa, A. Goto, T. Shimizu, T. Okubo, T. Mitani, R. Ikeda, J. Am. Chem. Soc. 126 (2004) 1614.

[4] F. H. Köhler, Probing spin densities by use of NMR spectroscopy. In Magnetism: Molecules to Materials, J. S. Miller, M. Drillon Eds. (WILEY-VCH, Weinheim, 2001) 379 .

[5] K. Liu, D. Ryan, K. Nakanishi, A. McDermott, J. Am. Chem. Soc. 117 (1995) 6897.

[6] M. Crozet, M. Chaussade, M. Bardet, L. Emsley, B. Lamotte, J.M. Mouesca, J. Phys. Chem. A 104 (2000) 9990.

[7] S. Ganapathy, V. P. Chacko, R. G. Bryant, M. C. Etter, J. Am. Chem. Soc.108 (1986) 3159.

[8] Y. Ishii, N.P. Wickramasinghe, S. Chimon, J. Am. Chem. Soc. 125 (2003) 3438.

[9] A.N. Clayton, C.M. Dobson, C.P. Grey, J. Chem. Soc., Chem. Commun. (1990) 72 .

[10] C.J. Groombridge, M.J. Perkins, J. Chem. Soc., Chem. Commun. (1991) 1164.

[11] K. Liu, J. Williams, H. Lee, M.M. Fitzgerald, G.M. Jensen, D.B. Goodin, A.E. McDermott, J. Am. Chem. Soc. 120 (1998) 10199.

[12] G. Maruta, S. Takeda, R. Imachi, T. Ishida, T. Nogami and K. Yamaguchi, J. Am. Chem. Soc. 121 (1999) 424.

[13] H. Heise, F.H. Köhler, F. Mota, J.J. Novoa, J. Veciana, J. Am. Chem. Soc. 121 (1999) 9659.

[14] J. Blumel, M. Herker, W. Hiller, F.H. Köhler, Organometallics 15 (1996) 3474.

[15] Y. Paik, J.P. Osegovic, F. Wang, W. Bowden, C.P. Grey, J. Am. Chem. Soc. 123 (2001) 9367.

[16] T.P. Spaniol, A. Kubo, T. Terao, J. Chem. Phys. 106 (1997) 5393.

[17] I. Sack, S. Vega, J. Magn. Reson. 145 (2000) 52.

[18] V.H. Crawford, H.W. Richardson, J.R. Wasson, D.J. Hodgson, W.E. Hatfield, Inorg. Chem. 15 (1976) 2107.

[19] P. Jeffrey, J.C. Thibeault, R. Hoffmann, J. Am. Chem. Soc. 97 (1975) 4884.

[20] S. Brooker, Eur. J. Inorg. Chem. (2002) 2535.

[21] W. Plass, A. Pohlmann, P. S. Subramanian, D. Srinivas, Z. Anorg. Allg. Chem. 628 (2002) 1377.

[22] G. La Monica, G.A. Ardizzoia, Coord. Chem. Rev. 46 (1997) 151.

[23] M.K. Ehlert, S.J. Rettig, A. Storr, R.C. Thompson, J. Trotter, Can. J. Chem. 69 (1991) 432. 
[24] M.G.B. Drew, P.C. Yates, F.S. Esho, J. Trocha-Grimshaw, A. Lavery, K.P. Mckillop, S.M. Nelson, J. Nelson, J. Chem. Soc., Dalton. Trans. (1988) 2995.

[25] D. Ajò, A. Bencini, F. Mani, Inorg. Chem. 27 (1988) 2437.

[26] E. Spodine, A.M. Atria, J. Valenzuela, J. Jalocha, J. Manzur, A.M. Garcia, M.T. Garland, O. Pena, J.Y. Saillard, J. Chem. Soc., Dalton. Trans. (1999) 3029 .

[27] H. Matsusima, H. Hamada, K. Watanabe, M. Koikawa, T. Tokii, J. Chem. Soc., Dalton Trans. (1999) 971.

[28] P. Frediani, D. Rovaib, M. Muniz-Mirandab, A. Salvinia, M. Caporalia, Catal. Commun. 2 (2001) 125.

[29] Cross polarization and ${ }^{1} \mathrm{H}$-decoupling, which were usually implemented in TOSS sequences, were not employed in our experiments.

[30] W.T. Dixon, J. Chem. Phys. 77 (1982) 1800.

[31] M.J. Frisch, G.W. Trucks, H.B. Schlegel, G.E. Scuseria, M.A. Robb, J.R. Cheeseman, V.G. Zakrzewski, J.A. Montgomery, Jr., R.E. Stratmann, J.C. Burant, S. Dapprich, J.M. Millam, A.D. Daniels, K.N. Kudin, M.C. Strain, O. Farkas, J. Tomasi, V. Barone, M. Cossi, R. Cammi, B. Mennucci, C. Pomelli, C. Adamo, S. Clifford, J. Ochterski, G.A. Petersson, P.Y. Ayala, Q. Cui, K. Morokuma, P. Salvador, J.J. Dannenberg, D.K. Malick, A.D. Rabuck, K. Raghavachari, J.B. Foresman, J. Cioslowski, J.V. Ortiz, A.G. Baboul, B.B. Stefanov, G. Liu, A. Liashenko, P. Piskorz, I. Komaromi, R. Gomperts, R.L. Martin, D.J. Fox, T. Keith, M.A. Al-Laham, C.Y. Peng, A. Nanayakkara, M. Challacombe, P.M.W. Gill, B. Johnson, W. Chen, M.W. Wong, J.L. Andres, C. Gonzalez, M. Head-Gordon, E.S. Replogle, J.A. Pople, GAUSSIAN 98, Revision A.11.1, Gaussian, Inc., Pittsburgh PA, 2001.

[32] I. Bertini, C. Luchinat, Coord. Chem. Rev. 150 (1996) 1.

[33] W.E. Estes, W.E. Hatfield, J.A.C. van Ooijen, J. Reedijk, J. Chem. Soc., Dalton Trans. (1980) 2121.

[34] H.M. McConnell, D.B. Chesnut, J. Chem. Phys. 28 (1958) 107. 